\title{
Recurrent Hodgkin Lymphoma
}

National Cancer Institute

\section{Source}

National Cancer Institute. Recurrent Hodgkin Lymphoma. NCI Thesaurus. Code C4937.

The reemergence of Hodgkin lymphoma after a period of remission. 